\title{
La terminología del deporte en los diccionarios generales del español*
}

\author{
Antoni Nomdedeu Rull \\ Universitat Pompeu Fabra
}

\section{INTRODUCCIÓN}

Una de las funciones básicas de los diccionarios generales es recopilar el léxico que conforma la lengua. Éstos han incorporado una gran cantidad de términos pertenecientes a distintos campos de conocimiento a raíz, sobre todo, de la irrupción de la mayoría de parcelas del saber en los medios de comunicación. Uno de estos campos que desde hace muchas décadas tiene un gran protagonismo en estos medios y que, en consecuencia, ocupa un papel destacado en nuestra sociedad es el deporte ${ }^{1}$.

La repercusión del deporte es tan grande y tan inmediata que se ha convertido en el centro de atención de poderosos organismos nacionales e internacionales. Desde el punto de vista lingüístico, toda la difusión que esto supone y que no es ajena prácticamente a nadie se traduce en la constante utilización de una serie de términos. De ahí, que su terminología presente un alto nivel de banalización ${ }^{2}$.

* Este estudio nace de una reelaboración de mi Trabajo de Investigación, La terminología deportiva de la prensa escrita en los diccionarios generales de español: análisis y propuesta lexicográfica, defendido en público el día 28 de junio de 2001 en el Instituto Universitario de Lingüística Aplicada de la Universidad Pompeu Fabra. Agradezco al profesor Cecilio Garriga Escribano de la Universidad Autónoma de Barcelona, director del mencionado trabajo de investigación, sus orientaciones para convertirlo en el presente estudio.

1 Véase, a modo de ejemplo, la página web elaborada por Castañón (1998), donde se tratan aspectos lingüísticos relacionados con el deporte.

2 Galisson (1979: 71-128) establece una clara distinción entre la banalización y la vul- 
En este trabajo, voy a analizar las consecuencias lingüísticas de la importancia social del deporte. Me centraré en la repercusión que su terminología tiene en la lengua general y más concretamente en los diccionarios generales de español.

El objetivo principal del presente estudio es, por lo tanto, analizar la terminología deportiva y observar cómo se representa en cinco diccionarios de lengua española:

- (DGLE) Diccionario General de la Lengua Española (1997), Barcelona, Biblograf.

- (DRAE) Real Academia Española (1992), Diccionario de la lengua española, Madrid, Espasa-Calpe.

- (GDLE) Gran diccionario de la lengua española LAROUSSE (1996), Barcelona, Larousse Planeta.

- (CLAVE) CLAVE, Diccionario de uso del español actual (1997), Madrid, Ediciones $\mathrm{SM}^{3}$.

- $(D E A)$ Seco, Manuel; Andrés, Olimpia; y Ramos, Gabino (1999), Diccionario del español actual, Madrid, Aguilar.

Concretamente, analizaré la presencia y ausencia de los términos en estos diccionarios, la marcación temática y las definiciones (no sólo el significado sino también las indicaciones temáticas que se hallan en el

garización. El primer fenómeno hace referencia a "la manifestation socialisée du processus d'accommodation", mientras que el segundo es "la manifestation individualisée" (1979: 75). Lo que significa que la banalización "fonctionne sur les bases d'un large consensus (souvent grâce à l'utilisation massive et à l'action uniformisante des media), se réalise de façon stable, habituelle et sert aux initiés [...] et que la vulgarisation est instable, occasionnelle (elle utilise circonstanciellement des moyens qui peuvent varier d'un locuteur à un autre, et sert à initier)" (p. 75).

3 He manejado las versiones en CD-ROM de los diccionarios CLAVE, DGLE, DRAE y $G D L E$. Cabe señalar que la versión en CD-ROM que he utilizado del $D G L E$ contiene toda la información introducida y modificada en la base de datos de la editorial desde 1990 hasta febrero de 1997. Presenta numerosos cambios y adiciones con respecto a las versiones en papel del Diccionario General Ilustrado de la Lengua Española $V O X(1992)$, en especial por la nueva redacción de muchas de las acepciones y la inclusión de neologismos, tecnicismos y extranjerismos de uso corriente. 
interior de las mismas) y realizaré algunas propuestas en relación con su tratamiento lexicográfico.

\section{LOS TÉRMINOS ANALIZADOS}

El conjunto de términos del deporte que analizaré en este estudio es de 933, tomado de distintos textos periodísticos pertenecientes a la prensa escrita. Se trata de una fuente que da cuenta del uso actual de la lengua en general, y de la utilización de la terminología deportiva en particular.

Para constatar el uso actual de los términos deportivos, los he documentado de manera sistemática en tres periódicos, dos de los cuales son periódicos de información general, El Mundo y El País, y el otro es un periódico de información estrictamente deportiva, El Mundo Deportivo $^{5}$. Con esto, consideraré los rasgos generales de los diccionarios para analizar una serie de aspectos lexicográficos, relacionados con los datos del corpus, a partir de sus particularidades ${ }^{6}$.

Los términos del corpus presentan la distribución temática siguiente:

4 Por ejemplo, el número de lectores de los principales periódicos deportivos en español en Cataluña y en España durante octubre de 1999 y mayo de 2000 es bastante elevado. En Cataluña, el periódico El Mundo Deportivo cuenta con 253.738 lectores diarios, el Sport con 244.296, el Marca con 116.532 y el $A s$ con 64.818. Así, sólo en Cataluña 679.384 personas leen diariamente periódicos deportivos. Por lo que se refiere al número de lectores en España, sólo contamos con los datos de los dos periódicos catalanes: El Mundo Deportivo es leído por unos 433.000 lectores diarios y el Sport por unos 377.000.

5 He vaciado un total de 482 artículos de prensa deportiva para confeccionar el corpus. El hecho de que se hayan extraído 244 términos del periódico El Mundo (26\%) y 180 de El País (19\%) da cuenta del importante lugar que ocupa la información deportiva en el ámbito de la prensa escrita en general. Aunque, como es lógico, la mayoría de términos, 509 , se ha obtenido del periódico especializado en deportes, El Mundo Deportivo (55\%), no sólo por tratarse del único de los tres periódicos que está especializado en la información deportiva, sino también porque he vaciado más artículos de este periódico que de ningún otro.

6 La presencia de los términos en los diccionarios y su representación, tanto desde el punto de vista de la marcación como de las definiciones. 


\begin{tabular}{|l|c|l|c|}
\hline Atletismo & 10 & Deportes en general & 43 \\
\hline Automovilismo & 6 & Esquí & 3 \\
\hline Baloncesto & 81 & Fútbol & 193 \\
\hline Balonmano & 12 & Fútbol Americano & 19 \\
\hline Boxeo & 6 & Golf & 4 \\
\hline Ciclismo & 19 & Hockey patines & 15 \\
\hline Deportes con portería & 14 & Motociclismo & 3 \\
\hline Deportes de anotación & 12 & Natación & 3 \\
\hline Deportes de equipo & 52 & Rugby & 1 \\
\hline Deportes de velocidad & 4 & Tenis & 40 \\
\hline & & Voleibol & 1 \\
\hline
\end{tabular}

Tabla 1 - Distribución temática de los términos del corpus ${ }^{7}$

Asimismo, los términos presentan una procedencia lingüística característica. Mostraré una tabla ilustrativa de los extranjerismos ${ }^{8} \mathrm{del}$ corpus en su idioma de origen en relación con los deportes en los que se emplean:

7 He clasificado cada término del corpus según el deporte en el que se emplea, por un lado, y según los rasgos característicos de algunos deportes (en cursiva), por el otro, pues hay términos que sólo se usan en un deporte y otros que se emplean en varios deportes a la vez. Así, considero que los términos bajo atletismo sólo se emplean en este deporte y los que se hallan bajo Deportes con portería se emplean en deportes que presentan esta estructura (he empleado este tipo de etiquetas para referirme de manera clara a aquellos términos que se emplean en varios deportes distintos y evitar, así, incluir un mismo término en muchos deportes).

8 En relación con los extranjerismos en la terminología del deporte, pueden verse los trabajos de Alzugaray (1982), Gómez Torrego (1995) o San Vicente (1998), y, más concretamente, sobre los anglicismos los de Marcos Pérez (1971), Pratt (1980), Mayoral (1992) o Nomdedeu y Márquez (2001). 


\begin{tabular}{|l|c|l|l|l|l|}
\hline & Inglés & Italiano & Portugués & Noruego & Croata \\
\hline Atletismo & 8 & & & & \\
\hline Automovilismo & 7 & & & & \\
\hline Baloncesto & 18 & & & & \\
\hline Boxeo & 6 & & & & \\
\hline Ciclismo & 5 & & & & \\
\hline Esquí & & & & 1 & \\
\hline Fútbol & 15 & 10 & & & 1 \\
\hline Fútbol Americano & 20 & & & & \\
\hline Golf & 12 & & & & \\
\hline Motociclismo & 3 & & & & \\
\hline Tenis & 23 & & & & \\
\hline General & 1 & 1 & 3 & & \\
\hline
\end{tabular}

Tabla 2 - Extranjerismos del corpus y deportes en los que se usan

Los deportes que presentan en la actualidad más extranjerismos son, como puede observarse, el fútbol, el tenis y el fútbol americano. Los dos primeros tienen muchos equivalentes en español para estos términos, mientras que el tercero no los tiene'.

9 Esto se debe, fundamentalmente, a la poca aparición que este deporte tiene en los medios de comunicación y, en consecuencia, a las pocas aportaciones de términos en español para complementar a los extranjerismos, en una primera fase, y convivir, en una segunda, con ellos. En algunos casos se sustituyen por equivalentes en español (árbitro en lugar de referee). 


\section{LOS TÉRMINOS EN LOS DICCIONARIOS GENERALES}

Es importante tener en cuenta los rasgos característicos de cada uno de los diccionarios para poderlos poner en relación con el Grado de Aceptación Terminológica (GAT) ${ }^{10}$, con el uso de unas marcas determinadas y con las definiciones, es decir, aspectos que son pertinentes a la hora de valorar los términos que recogen los diccionarios generales de español y cómo los recogen.

Entre los diccionarios que son objeto de este estudio, hay que diferenciar el diccionario normativo (DRAE) de los otros cuatro. De éstos, tres se declaran abiertamente de uso, CLAVE, DEA y GDLE, y uno de carácter general, el $D G L E$, que se considera a sí mismo un diccionario que tiene "interés por reflejar la situación actual de la lengua" (Alvar Ezquerra 1992: XXXVIII). No obstante, en los que se "registra un léxico muy heterogéneo, el que se supone que el usuario "normal" encontrará o usará en enunciados escritos y orales" (Haensch 1997: 148) se trata de diccionarios generales ${ }^{11}$.

Un aspecto que demuestra que son diccionarios de planta semejante es el número de lemas y de acepciones que incluyen:

10 Éste indica el porcentaje de términos empleados en un ámbito de especialidad que se recogen en los diccionarios generales. El GAT de cada uno de estos cuatro diccionarios lo analizaré en el apartado 2.1.

11 En Haensch (1997: 148), se indica qué suele registrar un diccionario general: léxico del nivel estándar, del nivel literario y formal, una selección de unidades léxicas del lenguaje coloquial y jergal, de lenguas especiales, de regionalismos, de americanismos, etc. Además, el propio Haensch (1997: 149-154) señala la existencia de distintos tipos de diccionarios generales, y sugiere una serie de denominaciones: diccionarios definitorios, de uso, de estilo, escolares, del español como lengua extranjera (para los dos últimos se propone el hiperónimo diccionarios didácticos). 


\begin{tabular}{|l|c|c|c|c|c|}
\hline & $D G L E$ & $D R A E$ & $G D L E$ & $C L A V E$ & $D^{12}$ \\
\hline Voces & $(100.000)^{13}$ & 83.500 & 70.000 & 55.000 & 75.000 \\
\hline Acepciones & $(200.000)$ & $(200.000)$ & 144.000 & 90.000 & 150.000 \\
\hline
\end{tabular}

Tabla 3 - Lemas y acepciones ${ }^{14}$

Me referiré a cuatro aspectos de tipo lexicográfico:

— al Grado de Aceptación Terminológica (GAT) ${ }^{15}$;

- a las marcas temáticas empleadas para el deporte y para los deportes $^{16}$;

- a las indicaciones temáticas y lingüísticas que aparecen en las definiciones;

- y a las propias definiciones.

12 Este diccionario pretende registrar "el léxico vivo de nuestra lengua en el tiempo presente" y se propone "inventariar el léxico que se usa, no solo el que se debe usar" (DEA 1999: XIII). Sus autores lo han realizado teniendo en cuenta una serie considerable de textos en español, aunque en algunos casos da la impresión de tratarse de un "diccionario de autor", pues la selección que se ha hecho de los autores con los que se documenta un término parece no ser aleatoria (los textos consultados suelen ser siempre los mismos: por ejemplo, en 97 ocasiones la fuente es el periódico $A b c$, lo que supone un $27,17 \%$ de los términos del corpus que recoge el $D E A$. Y en 20 de estas 97, el autor es G. Aróstegui).

13 Entre paréntesis incluyo los lemas y/o las acepciones a partir de un recuento realizado por mí ya que no se explicitaban en los diccionarios.

14 Aunque el CLAVE es el diccionario que lematiza menos voces, presenta unas características semejantes a los otros diccionarios. El DRAE es distinto al resto por el hecho de registrar el léxico oficial del español. No obstante, se trata de un diccionario general.

15 No sólo consideraré qué términos se recogen, sino que también atenderé a los que no se incluyen, pues de ambos datos se pueden extraer conclusiones interesantes para el estudio de la terminología del deporte en los diccionarios generales.

16 Aquí atenderé a las diferentes marcas o indicaciones del área temática "deporte" y a las distintas indicaciones de las voces extranjeras así como a la cuestión de qué se considera un extranjerismo en estos diccionarios. 
2.1. MACROESTRUCTURA: GRADO DE ACEPTACIÓN TERMINOLÓGICA (GAT)

Defino el GAT como la relación existente entre los términos deportivos del corpus hallados en los diccionarios generales de español y los términos del deporte de este corpus. El objetivo de este coeficiente es, pues, determinar el porcentaje de los términos del deporte del corpus que aparecen en los diccionarios generales de español a partir de una medida que varía entre 0 y 100 . El valor 0 representa la ausencia de términos del corpus en los diccionarios generales de español y 100 la presencia de todos los términos del corpus en estos diccionarios. El porcentaje resultante de esta relación me permitirá cuantificar el léxico propio de un lenguaje de especialidad que se recoge en los diccionarios generales. Formalmente, expreso este coeficiente de la manera siguiente:

$$
\mathrm{GAT}=\frac{T d d}{T d c} \times 100
$$

donde:

$T d d=$ Número de términos del deporte del corpus en los diccionarios $T d c=$ Número de términos del deporte del corpus

El GAT deportivo en los diccionarios tratados es, con la excepción del DRAE $(21 \%)^{17}$, bastante semejante (alrededor del 35\%) ${ }^{18}: 36,44 \%$ el $D G L E, 33,44 \%$ el $G D L E, 36,01 \%$ el $C L A V E$ y $38,26 \%$ el $D E A$.

Hay 146 términos que aparecen en los cinco diccionarios. El porcentaje de coincidencia es, pues, bastante elevado: el CLAVE tiene 181 términos que no aparecen en los otros cuatro diccionarios (aunque sí

17 En el apartado 1, ya he anotado cómo la posición normativista del diccionario académico frente a la lengua afecta a la aceptación o no de los términos deportivos. En este sentido, por ejemplo, incluye la marca de deporte (Dep.), pero, en cambio, sólo hay 119 términos con esta marca en todo el diccionario, cantidad ínfima si tenemos en cuenta que otros tantos deportes son, por lo menos, los que se practican en la actualidad. Hay, en cambio, abundante léxico antiguo en el DRAE: 9342 palabras tienen la marca de anticuado (ant.). Por lo tanto, de este diccionario se podrían suprimir muchos términos en desuso e incorporar léxico actual.

18 Hay que considerar la ventaja que supone para los diccionarios $D G L E, G D L E \mathrm{y}$ CLAVE tener al DRAE como punto de referencia. 
pueden aparecer en uno o dos de estos tres), el DEA $35^{19}$, el DGLE 157, el DRAE 41 y el GDLE 185 .

Asimismo, me referiré a los términos del corpus que no se recogen en los diccionarios. A pesar de que los diccionarios analizados se han publicado durante la década de los 90, no recogen términos que suelen aparecer con naturalidad en la prensa deportiva española actual. Los porcentajes de términos no incluidos son muy altos y suelen estar alrededor del $62 \%$ con la excepción del $D R A E^{20}$.

En relación con los términos no incluidos, hay 472 que no aparecen en ninguno de los cinco diccionarios (el 50,58\% del total del corpus). Parece, por lo tanto, que hay demasiados términos no incluidos en nuestros diccionarios que deberían recogerse, dado su uso generalizado en la prensa en español.

La poca presencia de términos en los diccionarios se observa, también, en la incorporación de extranjerismos ${ }^{21}$. Para dar cuenta de ello, muestro un cuadro con la relación de las voces extranjeras documentadas que se hallan en cada uno de los cinco diccionarios:

\begin{tabular}{|l|c|c|c|c|}
\hline & $\begin{array}{c}\text { Inglés } \\
100\end{array}$ & $\begin{array}{c}\text { Italiano } \\
10\end{array}$ & $\begin{array}{c}\text { Portugués } \\
2\end{array}$ & $\begin{array}{c}\text { Noruego } \\
1\end{array}$ \\
\hline DRAE & 1 & 0 & 1 & 1 \\
\hline$D G L E$ & 33 & 0 & 1 & 1 \\
\hline GDLE & 33 & 1 & 2 & 1 \\
\hline$C L A V E$ & 38 & 1 & 1 & 1 \\
\hline$D E A$ & 48 & 2 & 2 & 1 \\
\hline
\end{tabular}

Tabla 4 - Extranjerismos del corpus en los diccionarios generales de español

19 El $D E A$ sólo ha inventariado 35 términos que no se hallan en los otros cuatro diccionarios, a pesar de ser el último diccionario editado de los que he analizado.

20 El CLAVE 63,98\% (597), el DEA 61,73\% (576), el DGLE 63,55\% (593), el DRAE $78,99 \%$ (737) y el GDLE 66,55\% (621).

21 También me refiero a ellos porque constituyen una buena parte del corpus, concretamente, el $12,32 \%$. 
Estos datos reflejan la posición de los diccionarios frente a la inclusión de términos de otras lenguas. En este caso, los diccionarios $D G L E$, $G D L E$ y $C L A V E$ coinciden prácticamente en el número de extranjerismos incluidos, con 35,37 y 41 respectivamente, mientras que el diccionario que incluye un número mayor es el $D E A$, con un total de 53.

Merecen especial atención los datos del DRAE. Sólo incluye 3 términos en su diccionario (cadi, carioca, eslalon) de los 115 que he documentado y que considero extranjerismos, y no recoge términos que están en el sistema lingüístico del español desde hace mucho tiempo, muchos de los cuales están perfectamente consolidados, como break, doping, draft, drive, foto finish, goalaverage, hooligan, indoor, match ball, off-side, playoff, recordman, set, sprint, etc. Y únicamente incluye uno de los 100 anglicismos del corpus $(\text { cadi })^{22}$.

El DRAE considera extranjerismos deportivos chutar, córner, derbi, doparse, fútbol, gol, groggy, líder, penalti, récord o tenis, términos que están más consolidados si cabe que los anteriores. Esto ha conllevado que los usuarios no tengan conciencia de estar empleando un término perteneciente a un idioma que no es el suyo.

A partir del análisis de todos los datos mostrados, puede deducirse que los diccionarios siguen el mismo criterio a la hora de seleccionar un léxico común, ya que coinciden 22 de los 53 extranjerismos que incluye el $D E A, 35$ el $D G L E, 37$ el GDLE y 41 el CLAVE, lo que da cuenta de la poca variedad existente en los diccionarios de lengua española en cuanto a la inclusión de extranjerismos deportivos se refiere. Los 22 términos son:

$\begin{array}{llll}\text { ace } & \text { dribling } & \text { groggy } & \text { sprint } \\ \text { box } & \text { drive 1 } & \text { match ball } & \text { sprinter } \\ \text { break } & \text { drive 2 } & \text { playoff } & \text { stage } \\ \text { búnker } & \text { eagle } & \text { recordman } & \text { stick } \\ \text { carioca } & \text { eslalon } & \text { set } & \\ \text { dóping } & \text { green } & \text { sparring } & \end{array}$

22 En el prólogo del diccionario académico se dice, sin embargo, que "El DICCIONARIO que presentamos no pretende ser una enciclopedia abreviada, pero sí registrar y definir adecuadamente los términos cuyo empleo rebasa los límites de la especialidad y se atestigua diariamente en la prensa o en la conversación culta" (1992: VII). 
Pero la variedad es todavía menor si se tiene en cuenta que estos diccionarios tienen la ventaja, como ya he indicado antes, de tener al $D R A E$ como punto de referencia ${ }^{23}$.

Merecen un comentario aparte los términos del fútbol americano. Ninguno de los 16 extranjerismos del corpus que se emplean en este deporte está presente en los cinco diccionarios tratados ${ }^{24}$.

Se ha podido observar que los diccionarios $D E A, D G L E, G D L E \mathrm{y}$ $C L A V E$ tienen más en cuenta que el DRAE la presencia de extranjerismos, aunque también suelen omitir algunos términos de uso bastante frecuente en la terminología del deporte. El $D E A$ no recoge términos de uso habitual en el deporte como break-point, calcio, final four, passing o rabona. El DGLE no tiene en cuenta extranjerismos tan usuales como all-star, birdie, calcio, catenaccio, draft, eslalom, hat trick o hooligan. Faltan, en el GDLE, bogey, pole position, putt, quarterback o rookie. Y en el diccionario CLAVE no se incluyen términos como allei-hoop, hat trick, rookie o scudetto. Con todo, la diferencia entre estos cuatro diccionarios y el académico es muy notable en la actualidad, por lo menos en cuanto a la presencia de la terminología del deporte y de sus extranjerismos se refiere.

\subsection{MicROESTRUCTURA}

Por lo que se refiere al conjunto de informaciones que en los diccionarios siguen a la entrada, he atendido a las marcas, a las definiciones

23 La influencia del diccionario académico en el resto de diccionarios modernos es innegable (Alvar Ezquerra 1992: 22), pues se considera "el punto de partida de todos los diccionarios modernos: recoge el léxico "oficial" del español" (Garriga 1991: 152).

24 Cornerback, defensive back, down, end-zone, field-goal, free savety, fullback, fumble, kicker, NFL, punter, quarterback, running back, Super Bowl, touchdown, wide receiver. Es un deporte poco difundido en España. Se ha comenzado a divulgar gracias a los medios de comunicación y a la creación de una liga europea (European Football League) y su difusión es especialmente relevante en Cataluña y en catalán, debido a la participación del equipo Barcelona Dragons en esta competición. La repercusión social del fútbol americano comienza a ser relevante, aunque no sea como la de otros deportes. 
y a las indicaciones temáticas y lingüísticas que se hallan en el interior de las definiciones.

\subsubsection{Análisis de las marcas ${ }^{25}$}

El proceso de selección de los términos utilizados en un lenguaje de especialidad que deben inventariarse en un diccionario general es sumamente complejo. Mediante el empleo de marcas referidas al campo de aplicación del término se facilita al usuario información diatécnica $^{26}$. Y el empleo riguroso de estas marcas temáticas no sólo contribuye a reducir el tamaño ${ }^{27}$ del diccionario, sino también a que el usuario identifique rápidamente y sin confusiones el campo de aplicación de la acepción que busca ${ }^{28}$. Las marcas son, pues, una parte muy importante del artículo lexicográfico.

Por un lado, atenderé a las marcas temáticas y, por el otro, a la marca lingüística de anglicismo, pues la presencia de voces en inglés en el corpus es abundante.

25 En Nomdedeu (2001) se aborda esta cuestión poniendo el énfasis en el caso particular del léxico del fútbol y del deporte.

26 Con esta denominación Hartmann (1998, s. v. diatechnical information) se refiere a un "usage feature which associates a word or phrase with a particular SUBJECT FIELD".

27 Aunque no tiene demasiado sentido con la creciente irrupción, pero aún testimonial, en el mercado de los diccionarios en soporte electrónico. Gutiérrez Cuadrado (1996: 102) señala que "quizá es una exigencia editorial".

28 En relación con la claridad y la sistematicidad del empleo de las marcas, Garriga (1996: 105) dice que "todos los trabajos que se ocupan del tema de las marcas se refieren a dos aspectos para que estas indicaciones sean aprovechables por el usuario: la necesidad de establecer un criterio coherente sobre el valor de cada una de ellas, y la de que esta información se proporcione de forma clara y sistemática. Las propuestas sobre cómo debe expresarse esta información en el diccionario recomiendan la codificación de la misma, destinándole un espacio fijo en el artículo lexicográfico, y separándola en todo momento de la definición. Esta función la cumplen, a veces, las abreviaturas, aunque no con el rigor y la precisión deseables". En Garriga (1997) se pueden encontrar consideraciones sobre marcas de uso. 


\subsubsection{Marcas temáticas}

Entiendo por marca temática aquella información acerca del área temática de la acepción definida que suele presentarse en forma de abreviatura y que siempre precede a la definición ${ }^{29}$. La marca temática predominante es la de deporte. Es una marca de empleo general en los cinco diccionarios analizados, mientras que las referentes a determinados deportes (automovilismo, baloncesto, ciclismo, esgrima, fútbol e hípica) sólo se emplean, por vez primera en la lexicografía general en español, de manera generalizada y sistemática en el DEA.

a) Términos marcados con "deporte"

En el diccionario académico, 119 palabras tienen la marca temática Dep., 39 de las cuales están presentes en el corpus (32,77\%). Muchas de estas palabras marcadas no coinciden con las que tienen el nombre de algún deporte en la definición. Así, por ejemplo, la palabra cadi (del inglés caddie) tiene el término golfen la definición y, en cambio, no tiene la marca de deporte. Lo mismo sucede con términos del boxeo como asalto, croche $e^{30}$, nulo o cuadrilátero; en los términos de la natación se hallan algunos casos interesantes que no tienen la marca de deporte (braza y mariposa) y casos que sí (croly espalda); términos del ciclismo como vuelta; o términos del fútbol como cabecear, cañonazo, centrocampista, chutar, futbolista, gol y penalti que no tienen marca de deporte y otros como centrar, saltar o tarjeta que sí la tienen.

29 Martínez de Sousa (1995: 261) prefiere emplear marca de materia. Lo define del modo siguiente: "Marca que afecta a la unidad léxica de entrada para indicar la ciencia, técnica, profesión o especialidad a que pertenece, expresada con la abreviatura correspondiente". Hay autores como Fajardo (1994: 131-143 y 1997: 43-45) que prefieren emplear marcas técnicas o como Hartmann (1998) que emplea field label.

En relación con lo que se entiende por marca, Fajardo (1994: 131-143) y Gutiérrez Cuadrado (1996: 95-106) abordan esta cuestión. Aquí emplearé el término marca para referirme a las abreviaturas y a palabras referentes al ámbito temático que no forman parte de la definición y que se emplean sistemáticamente. Y emplearé el término indicación para referirme a la información acerca del ámbito temático que se halla dentro de la definición. El empleo de éstas suele ser, como se verá, irregular.

30 Los términos croché, nulo y crol no forman parte del corpus. Ahora los considero para constatar esta falta de sistematicidad. 
Los términos marcados con Dep. son:

$\begin{array}{lll}\text { a domicilio (s. v. domicilio) } & \text { escudería } & \text { prórroga } \\ \text { arrojar la toalla (s. v. toalla) } & \text { eslalon } & \text { revés } \\ \text { banquillo } & \text { espalda } & \text { ronda } \\ \text { batir } & \text { fondo } & \text { salto de longitud (s. v. salto) } \\ \text { calentamiento } & \text { gancho I } & \text { servicio } \\ \text { campo } & \text { groggy } & \text { tanteador } \\ \text { centro } & \text { guardameta } & \text { tapón } \\ \text { colegiado } & \text { marca 1 } & \text { terreno } \\ \text { córner } & \text { meta 1 } & \text { tirar la toalla } \text { (s. v. toalla) } \\ \text { decatlón } & \text { mundial } & \text { tocado } \\ \text { división } & \text { pelotón } & \text { torneo } \\ \text { doparse } & \text { personal } & \text { triple salto } \text { (s. v. salto) } \\ \text { entrada } & \text { pívot } & \text { velocista }\end{array}$

En cambio, no se marcan términos también deportivos como alinear, alineación, braza, cabecear, canasta, defensa, delantero, etc.

El DRAE incluye la marca Esgr. (esgrima) en 122 ocasiones $^{31}$. Es el primer caso en que se recoge una marca referente a un deporte determinado en la lexicografía general del español, aunque, como he señalado ya, el diccionario que lo hace de manera sistemática por primera vez es el $D E A^{2}$.

Por lo que respecta al $D G L E$, los términos del ámbito deportivo se indican con "DEPORTES". Hay 195 términos que presentan esta indicación, de los 340 del corpus que el DGLE incluye (57,35\%). De estos 195 términos, hay algunos que tienen alguna indicación temática en relación con el deporte concreto en el que se emplean, mientras que otros no la tienen:

ariete. (Del lat. Aries, carnero, ariete). 2. Delante- s.m.

ro centro de un equipo de fútbol.

DEPORTES

31 Se trata de un deporte de escasa aparición en los medios de comunicación y del que no tengo ningún término documentado.

32 Las marcas de deportes que se emplean en este diccionario son: Autom (automovilismo), Balonc (baloncesto), Cicl(ciclismo), Esgr (esgrima), Fút (fútbol) e Híp (hípica). 
cabecear. 7 Golpear la cabeza: el delantero centro v.tr.

cabecea el esférico muy bien.

DEPORTES

En los 145 términos restantes, es decir, en los que no tienen la indicación "DEPORTES" en la definición, hay algunos que no tienen indicaciones sobre el deporte en el que se emplean y otros que sí la tienen, como se muestra en la tabla siguiente:

\begin{tabular}{|l|l|}
\hline $\begin{array}{l}\text { Con "DEPORTES" } \\
\text { En la definición }\end{array}$ & $\begin{array}{l}\text { alero, amateur, amistoso, antideportivo, área, ariete, } \\
\text { artillero, asistencia, bandeja, banquillo, base, batir, } \\
\text { blocar, bogey, etc. }\end{array}$ \\
\hline $\begin{array}{l}\text { Sin "DEPORTES" } \\
\text { En la definición }\end{array}$ & $\begin{array}{l}\text { alineación, anotador, box, boxeador, cantera, carrilero, } \\
\text { colider, colista, copero, crack, decatlón, etc. }\end{array}$ \\
\hline
\end{tabular}

Tabla 5 - Términos del corpus en el DGILE con "DEPORTES" o sin "DEPORTES" en la definición

No existe ningún aspecto que motive que ariete esté marcado y carrilero no, ya que ambos términos se emplean en el fútbol para designar demarcaciones concretas.

En el GDLE 278 términos presentan la indicación "DEPORTES" en la definición ${ }^{33},(89,1 \%)$ de los 312 términos del corpus que se recogen, lo que da cuenta de la sistematicidad de este diccionario en cuanto a la indicación del área temática "DEPORTES” se refiere. Sólo 34 términos del corpus $(10,9 \%)$ no tienen esta indicación:

$\begin{array}{ll}\text { a la defensiva (s.v. defensivo) } & \text { estrella } \\ \text { anotador } & \text { filial } \\ \text { astro } & \text { ganar la partida } \text { (s.v. partida) } \\ \text { balón } & \text { liderato } \\ \text { calentar } & \text { liderazgo } \\ \text { campeonato } & \text { monoplaza } \\ \text { cantada } & \text { pelotear } \\ \text { cantera } & \text { peloteo }\end{array}$

33 Recuérdese que este diccionario no incluye marcas temáticas, sino que indica el área temática del término o acepción mostrando el nombre de la disciplina al lado del artículo lexicográfico mediante códigos temáticos. 


$\begin{array}{ll}\text { carioca } & \text { plato } \\ \text { club } & \text { poner la directa (s. directo) } \\ \text { corticoides } & \text { punto } \\ \text { dejar fuera de combate (s.v. combate) } & \text { rival } \\ \text { empatar } & \text { suplente } \\ \text { entrar en juego (s.v. entrar) } & \text { tartán } \\ \text { entrenador } & \text { tiempo } \\ \text { entrenamiento } & \text { variante } \\ \text { entrenarse } & \text { volea }\end{array}$

El diccionario CLAVE no presenta ningún tipo de marca que indique si se trata o no de un término del deporte pero, en cambio, presenta una serie de indicaciones sobre si el término se utiliza en el fútbol (70 acepciones), en el baloncesto (33), etc., o si se trata de un término del deporte en general $^{34}$. Por ejemplo:

ariete sustantivo masculino. 2. En fútbol, delantero centro de un equipo: La función principal del ariete es marcar goles.

Notas: Etimología: Del latín aries (carnero), por la semejanza entre la forma de usar el ariete y la forma de envestir [sic] del carnero.

Finalmente, el DEA marca con Dep 123 términos (34,45\%) del total que recoge. Pero hay que insistir en que se trata de un diccionario que introduce por vez primera en la lexicografía general del español diferentes marcas temáticas de un modo generalizado y sistemático para referirse a deportes determinados como el automovilismo (Aut.), el baloncesto (Balonc.), el ciclismo (Cicl.), la esgrima (Esgr.), el fútbol (Fút.) y la hípica (Híp.).

Por lo tanto, y a modo de resumen, en la tabla siguiente aparece la cantidad de términos marcados temáticamente con Dep, Dep., DEP. o DEPORTES en cuatro de los diccionarios estudiados:

\begin{tabular}{|c|c|c|c|}
\hline$D R A E$ & DGLE & GDLE & DEA \\
\hline $\mathbf{3 9}(D e p)$ & $\mathbf{1 9 5}$ (DEPORTES) & $\mathbf{2 7 8}$ (DEPORTES) & $\mathbf{1 2 3}($ Dep $)$ \\
\hline
\end{tabular}

Tabla 6 - La marca de deporte en los diccionarios generales de español

34 En 3.2.2.1, atenderé a esta cuestión detalladamente. 
b) Otras marcas de deportes

Ya he indicado que el único de los cinco diccionarios analizados que incluye marcas de deportes de manera generalizada, además de la genérica "deporte", es el $D E A$. Se trata de una aportación importante y conveniente que permite ubicar, sin duda, el término buscado con mayor precisión y surge como consecuencia de la relevancia de la terminología del deporte en la lengua general. En este diccionario, se emplea la marca Fút. en 77 términos de los 357 que incluye del corpus $(21,56 \%)$ para los términos que se emplean en el fútbol:

interior II $m \mathbf{7}$ (Fút) Jugador cuyo puesto está entre el delantero centro y un extremo. | M. Garóstegui Sabc 27.4.69, 32: Había entonces interiores como Igoa, Panizo y Hernández.

En cuatro ocasiones se emplea la marca $\mathrm{CiCl}$ para los términos empleados en el ciclismo:

contrarreloj adj invar ( $\mathrm{Cicl}$ ) [Etapa o carrera] contra reloj (-RELOJ). Frec $n$ f. Tb fig. | País 16.9.84, 57: Induráin gana en la contrarreloj del Tour del Porvenir.

Y en diez ocasiones se emplea la marca Balonc para los términos empleados en el baloncesto:

escolta $\mathbf{C} m$ y $f \mathbf{5}$ (Balonc) Jugador que actúa como apoyo del base. | Shoy 19.9.92, 32: Basket: 92-93 .. 5 Ismael Santo .. Escolta 6 Fernando Romay .. Pivot.

Como se observa, la precisión con la que se delimita el ámbito temático del término es mucho mayor. Además, las marcas empleadas son claras y tienen un significado bastante transparente.

2.2.1.2. La marca de "anglicismo"

El DRAE sólo incluye un anglicismo de los 100 que he documentado y, por lo tanto, no se puede establecer ninguna conclusión en relación con su sistematicidad o asistematicidad en este sentido ${ }^{35}$. El anglicismo en cuestión es caddie:

35 El diccionario académico recoge otros dos extranjerismos, de los 115 totales del corpus: carioca (portugués) y eslalon (noruego). 
cadi $^{2}$ Del ing. caddie.

1. m. Muchacho que lleva los palos de los jugadores de golf.

Por lo que respecta al DGLE, se recogen 33 términos de los $100 \mathrm{del}$ corpus. En éstos, oscilan las marcas "voz ing.", "ANGLICISMO", "ing.", "anglic." y "voz inglesa". Además, se recogen términos ingleses sin ninguna marca sobre su origen. Véanse estos datos en una tabla:

\begin{tabular}{|c|l|}
\hline sin marca de "anglicismo" & bogey, foto-finish, putt, superwelter \\
\hline anglic. & stick \\
\hline ANGLICISMO & catch, goalaverage, sprint, stage \\
\hline ing. & $\begin{array}{l}\text { basquet, chutar, córner, derby, doparse, fútbol, } \\
\text { gol, hockey patines, líder, meeting, nocáut, penal- } \\
\text { ti, rally, récord, set, tenis, welter. }\end{array}$ \\
\hline voz ing. & dóping \\
\hline voz inglesa & $\begin{array}{l}\text { ace, box, caddie, dribbling, drive (1), drive (2), } \\
\text { eagle, green, let, match ball, off-side, playoff, } \\
\text { ring, rough, sparring, sprinter, tee. }\end{array}$ \\
\hline
\end{tabular}

Tabla 7 - La marca de anglicismo e indicaciones en el DGLE

En cuanto al GDLE, recoge 38 términos de los 100 del corpus. De éstos, 35 presentan la indicación "voz inglesa" y 3 la indicación "expresión inglesa":

\begin{tabular}{|c|l|}
\hline voz inglesa & $\begin{array}{l}\text { ace, basquet, birdie, box, break, búnker, caddie, } \\
\text { catch, chut, club, crack, derby, dóping, dribbling, } \\
\text { drive (2), eagle, game, green, hockey patines (s.v. } \\
\text { hockey), hooligan, let, rally, recordman, ring, set, } \\
\text { smas, sparring, sprint, sprinter, stage, stick, tee, } \\
\text { tie break, touchdown, welter. }\end{array}$ \\
\hline expresión inglesa & match ball, passing shot, playoff. \\
\hline
\end{tabular}

Tabla 8 - Las indicaciones de anglicismo en el GDLE

A pesar de que este diccionario considera, por ejemplo, playoff una "expresión inglesa" y tie break una "voz inglesa" -no se observan di- 
ferencias notables entre estos dos términos para que uno sea considerado una expresión y el otro una voz-, es el diccionario que trata de manera más sistemática, después del $D E A$, las indicaciones de extranjerismo.

En el $C L A V E$, se hallan dos tipos de indicaciones: una al lado del lema, (anglicismo), y otra que se incluye en el apartado de "Etimología", "Del inglés..." ${ }^{36}$. Se incluyen 29 términos con la indicación "(anglicismo)" en la definición y 8 términos en los que se indica en el apartado "Uso" que se trata de "un anglicismo innecesario":

\begin{tabular}{|l|l|} 
anglicismo & $\begin{array}{l}\text { ace, all star, basquet, birdie, bogey, break, crack, draft, } \\
\text { dribbling, drive (1), drive (2), eagle, game, goalaverage, } \\
\text { green, hooligan, paddock, passing shot, pole position, putt, } \\
\text { rally, recordman, set, sparring, sprint, stage, stick, tie }\end{array}$ \\
\hline & $\begin{array}{l}\text { break, transfer. } \\
\text { del inglés... }\end{array}$ \\
chut, chutar, córner, derby, doparse, fútbol, gol, groggy,
\end{tabular}
lider, penalti, récord, tenis.

Tabla 9 - Las indicaciones de anglicismo en el CLAVE

Las indicaciones sobre el uso que se recomiendan en este diccionario no suelen ir acompañadas de una propuesta para sustituir el término que está en otra lengua, por lo que no favorece el hecho de que se pongan en circulación nuevos términos en español para que, como mínimo, acompañen a los extranjerismos. Además, esta indicación se lleva a cabo de un modo bastante asistemático. Hay 26 extranjerismos del corpus que he hallado en el diccionario CLAVE y aparecen acompañados por tres tipos de indicaciones en el apartado Notas que suele completar muchos artículos:

— "Es un anglicismo (italianismo, etc.) innecesario".

36 Conviene señalar la diferencia entre la indicación "(anglicismo)" y "Del inglés...". La primera alude a los términos todavía no consolidados en la lengua española y que, por lo tanto, son reconocidos por los hablantes como términos no españoles. La segunda indica aquellos términos de origen inglés que se han consolidado absolutamente en el sistema lingüístico español. 
— "Su uso es innecesario".

— "Es innecesario el uso del anglicismo (término noruego, etc.)".

A continuación, muestro una tabla que ilustra los extranjerismos del corpus que presentan cada una de estas indicaciones:

\begin{tabular}{|c|l|}
\hline "Es un anglicismo (italianismo, etc.) & ace, coach, dóping, game, libero, off- \\
\hline innecesario" & side, ring, tie-break, smash \\
"Su uso es innecesario" & amateur, blaugrana, birdie, bogey, \\
& draft, dribling, eagle, match ball, \\
& playoff, pole position, putt, stage, \\
\hline & transfer \\
"Es innecesario el uso del anglicismo & antidóping, derby, penalty, slalom \\
\hline
\end{tabular}

(término noruego, etc.)"

Tabla 10 - Indicaciones sobre los anglicismos en al apartado Notas en el CLAVE

Y finalmente, el $D E A$ recoge 48 anglicismos de los 100 del corpus, en todos los casos con la marca "ing". Además, van siempre acompañados de la "pronunciación corriente":

break (ing; pronunc corriente, /brek/; pl normal, -S) $m 2$ (Tenis) Ruptura de servicio. $\mid$ As 2.7.75, 29: Llegaron a empatar a siete juegos, cuando Evonne tuvo una fantástica racha de inspiración .., logrando el "break", que sería decisivo, ya que con 8-7 entró para ganar sobre el saque. $\mathrm{Ya}$ 15.11.91, 50: Agassi contó con tres bolas de "break", pero no fue capaz de ap[ro]vecharlas.

El $D E A$ es el diccionario que recoge más anglicismos y el que los marca de manera más sistemática.

\subsubsection{Análisis de las definiciones}

Comenzaré por analizar las indicaciones sobre "deporte" en los términos y atenderé al contenido de las definiciones.

\subsubsection{Voces referidas a deportes en las definiciones}

Es interesante observar qué voces referidas a deportes aparecen en las definiciones de los términos del corpus halladas en los cinco dic- 
cionarios analizados para dar cuenta de la diferente representatividad de los deportes en nuestra lexicografía. Para demostrarlo, en el cuadro siguiente expongo los términos del corpus que tienen el nombre de algún deporte en la definición en los diccionarios analizados:

\begin{tabular}{|l|c|c|c|c|c|}
\hline & DRAE & DGLE & GDLE & CLAVE & DEA \\
\hline Atletismo & 3 & 4 & 4 & 9 & 3 \\
\hline Automovilismo & 0 & 0 & 0 & 0 & 0 \\
\hline Baloncesto & 7 & 19 & 19 & 33 & 1 \\
\hline Balonmano & 0 & 1 & 3 & 2 & 0 \\
\hline Boxeo & 7 & 10 & 6 & 10 & 3 \\
\hline Ciclismo & 1 & 5 & 5 & 1 & 2 \\
\hline Esquí & 2 & 5 & 4 & 5 & 2 \\
\hline Fútbol & 32 & 55 & 51 & 70 & 13 \\
\hline Fútbol Americano & 0 & 2 & 2 & 1 & 0 \\
\hline Golf & 2 & 15 & 11 & 8 & 1 \\
\hline Natación & 4 & 4 & 4 & 5 & 2 \\
\hline Tenis & 4 & 13 & 27 & 24 & 3 \\
\hline
\end{tabular}

Tabla 11 - Nombre de algún deporte en la definición

Una vez más, los términos empleados en el fútbol son más numerosos que el resto. También cabe destacar la poca aparición de términos del automovilismo (ninguno en los cinco diccionarios), del balonmano, del fútbol americano o de la natación. De estos datos también se infiere que el $D R A E$ incluye menos términos deportivos en relación con los cuatro diccionarios restantes. El único caso en el que el diccionario académico incluye más términos con el nombre de algún deporte en la de-

37 Seguramente este dato se debe al conocimiento, por parte de los académicos, de un deporte de frecuente aparición en los diversos medios de comunicación hace bastantes años, como era el boxeo, y a la existencia de una serie de boxeadores españoles de pres- 
finición es en el boxeo ${ }^{37}$ en comparación con el GDLE (7 apariciones en el $D R A E$ y 6 en el $G D L E)^{38}$. El hecho de que aparezcan pocos nombres de deportes en las definiciones del $D E A$ se explica porque se trata de un diccionario que incorpora diferentes marcas temáticas de manera sistemática referidas a diversos deportes, lo que hace innecesaria la inclusión de nombres de deportes en las definiciones.

En los diccionarios generales del español aparecen unas indicaciones en las definiciones acerca del deporte en el que se emplean (indicaciones temáticas ${ }^{39}$, pero se observa que no se llevan a cabo de manera sistemática. Por ello, mostraré los diferentes tipos de indicaciones en relación con el deporte en general, por un lado, y el fútbol, por el otro, pues son las más numerosas y variadas.

Respecto a las definiciones del $D R A E$, hay voces en cuya definición se indica que se trata de un término o acepción utilizado "En el fútbol", "En el fútbol y otros deportes", "En deportes" o "En algunos deportes", etc.:

\begin{tabular}{|c|l|}
\hline En algunos deportes & despejar, despeje, entrada, pegada, portero, \\
\hline & tiempo muerto (s.v. tiempo) \\
\hline En deportes & anotar \\
En el fútbol & ariete, cabecear, centro, chutar, saque de es- \\
\hline \multirow{3}{*}{ En el fútbol y otros } & $\begin{array}{l}\text { quina (s.v. saque) } \\
\text { defensa, delantero, delantero centro deportes } \\
\text { (s.v. delantero), extremo, interior, línea de co- } \\
\text { bertura (s.v. cobertura), penalti, regate, rema- }\end{array}$ \\
\hline
\end{tabular}

tigio internacional que provocaba una gran aparición de este deporte en los medios. Esto último se convierte en un factor determinante para la difusión de un deporte en los diversos medios de comunicación de un país. Un ejemplo reciente es el de la Fórmula 1.

38 Comentaré más detalladamente el caso del DEA más adelante, dentro de este mismo apartado.

39 Entiendo por indicación temática aquella información acerca del área temática de la acepción definida que no se presenta en forma de abreviatura y que siempre se halla en el interior de la definición. 


\begin{tabular}{|c|l|}
\hline & tar, remate, travesaño \\
\hline En ciertas competiciones & colista \\
\hline $\begin{array}{c}\text { En el fútbol o en otros juegos } \\
\text { En el juego del fútbol y } \\
\text { otros semejantes }\end{array}$ & $\begin{array}{c}\text { fuera de juego (s.v. juego) } \\
\text { gol, portería }\end{array}$ \\
\hline $\begin{array}{c}\text { En el juego del fútbol } \\
\text { En fútbol y algunos }\end{array}$ & $\begin{array}{c}\text { golear } \\
\text { marcar }\end{array}$ \\
\hline otros deportes & \\
\hline
\end{tabular}

En fútbol y otros juegos

meta (3)

Tabla 12 - Indicaciones temáticas en las definiciones del $D R A E$

Estas indicaciones se hallan tanto en las definiciones de términos marcados con Dep. como en las de otros no marcados temáticamente. No obstante, no me voy a detener en el análisis de qué términos de los marcados y de los no marcados vienen acompañados, en sus definiciones, por indicaciones temáticas de este tipo ${ }^{40}$. En este sentido, sólo indico que hay dos términos que tienen alguna indicación sobre el deporte en el que se emplea el término y además presentan la marca de deporte en la definición:

entrada 23. Dep. En algunos deportes, encuentro entre dos jugadores contrarios, generalmente con el fin de arrebatarle la pelota uno al otro.

centro 24. Dep. En el fútbol, acción y efecto de centrar.

En relación con las definiciones, el DGLE se muestra falto de sistematicidad a la hora de indicar temáticamente el campo de aplicación del término:

en deporte

en los deportes casillero

marca (1), plusmarca

40 Considero que se trata de un análisis que conduce a la formulación de otras propuestas, a las que me referiré en otra ocasión. 


\begin{tabular}{|c|c|}
\hline $\begin{array}{l}\text { en algunos deportes } \\
\text { en ciertos deportes }\end{array}$ & $\begin{array}{l}\text { portero, regate, vaselina } \\
\text { equipo }\end{array}$ \\
\hline en determinados juegos o deportes & servir \\
\hline en diversos juegos o deportes & torneo \\
\hline en ciertos juegos o deportes & campeonato \\
\hline en deportes de equipo & anotar \\
\hline en ciertos deportes de equipo & demarcación \\
\hline en algunos deportes de equipo & entrada \\
\hline en las competiciones deportivas & colegiado \\
\hline en una competición deportiva & playoff \\
\hline en las agrupaciones deportivas & seleccionador \\
\hline $\begin{array}{c}\text { en las agrupaciones o equipos } \\
\text { deportivos }\end{array}$ & entrenador \\
\hline en el fútbol & combinar, interior, travesaño \\
\hline en el juego del fútbol & $\begin{array}{l}\text { artillero, blocar, botar, cabecear, cen- } \\
\text { tro, centrocampista, chutar, córner, } \\
\text { dribling, empalmar, fuera de juego } \\
\text { (s.v. fuera), golpe franco, guardameta, } \\
\text { peinar, pena máxima, pichichi, rasear, } \\
\text { rematar, remate, osca, tijera, zurdazo }\end{array}$ \\
\hline
\end{tabular}

esp. en fútbol

pared

Tabla 13 - Indicaciones temáticas en las definiciones del DGLE

Por ejemplo, se observa que en la definición de un verbo como combinar se incluye la indicación temática "en el fútbol", mientras que en las de verbos empleados también en este deporte como blocar, cabecear, chutar o peinar se halla "en el juego del fútbol". Las indicaciones "en deportes de equipo", "en ciertos deportes de equipo" y "en algunos deportes de equipo" podrían unificarse bajo una sola indicación. Lo mismo sucede entre "en diversos juegos o deportes", "en ciertos juegos o deportes" y "en determinados juegos o de- 
portes" donde el único elemento cambiante es el adjetivo antepuesto al nombre "juegos".

Por su parte, el GDLE es el diccionario más sistemático a la hora de indicar temáticamente el campo de aplicación del término, aunque, como se muestra en la tabla siguiente, no en todos los casos:

\begin{tabular}{|c|c|}
\hline en algunos deportes & $\begin{array}{l}\text { árbitro, área, meta (1), portero, servi- } \\
\text { cio, zurdazo }\end{array}$ \\
\hline en ciertos deportes & demarcación, servir \\
\hline en ciertas pruebas deportivas & bonificación \\
\hline en una competición deportiva & marcador (1), récord \\
\hline en competiciones deportivas & plusmarca \\
\hline en algunas competiciones deportivas & tanto \\
\hline en algunos deportes de equipo & doblete, marco \\
\hline en algunos deportes de pelota & internada \\
\hline en los deportes de pelota & disparo \\
\hline en juegos de balón y pelota & lanzamiento \\
\hline en los juegos y deportes & pase \\
\hline en el fútbol & $\begin{array}{l}\text { chut, derechazo, rasear, tijera, vaseli- } \\
\text { na }\end{array}$ \\
\hline en fútbol y otros deportes & remate \\
\hline
\end{tabular}

en el fútbol y otros deportes

córner, gol, penalti, rematar, saque de banda (s.v. saque)

en el fútbol y otros deportes de equipo central, extremo, lateral

Tabla 14 - Indicaciones temáticas en las definiciones del GDLE

Como se observa, hay muchas indicaciones temáticas que, como propongo en este estudio, deberían reducirse y sistematizarse. Además, se emplean en pocas ocasiones en este diccionario y, a menudo, de ma- 
nera bastante sistemática. Con todo, existen algunos casos que pueden mejorarse: el término derechazo se incluye bajo la indicación temática "en el fútbol" y zurdazo bajo "en algunos deportes"; se emplean las indicaciones "en el fútbol y otros deportes" y "en fútbol y otros deportes" cuando podrían recogerse en una; y las indicaciones "en una competición deportiva", "en competiciones deportivas" y "en algunas competiciones deportivas" regularmente podrían unificarse.

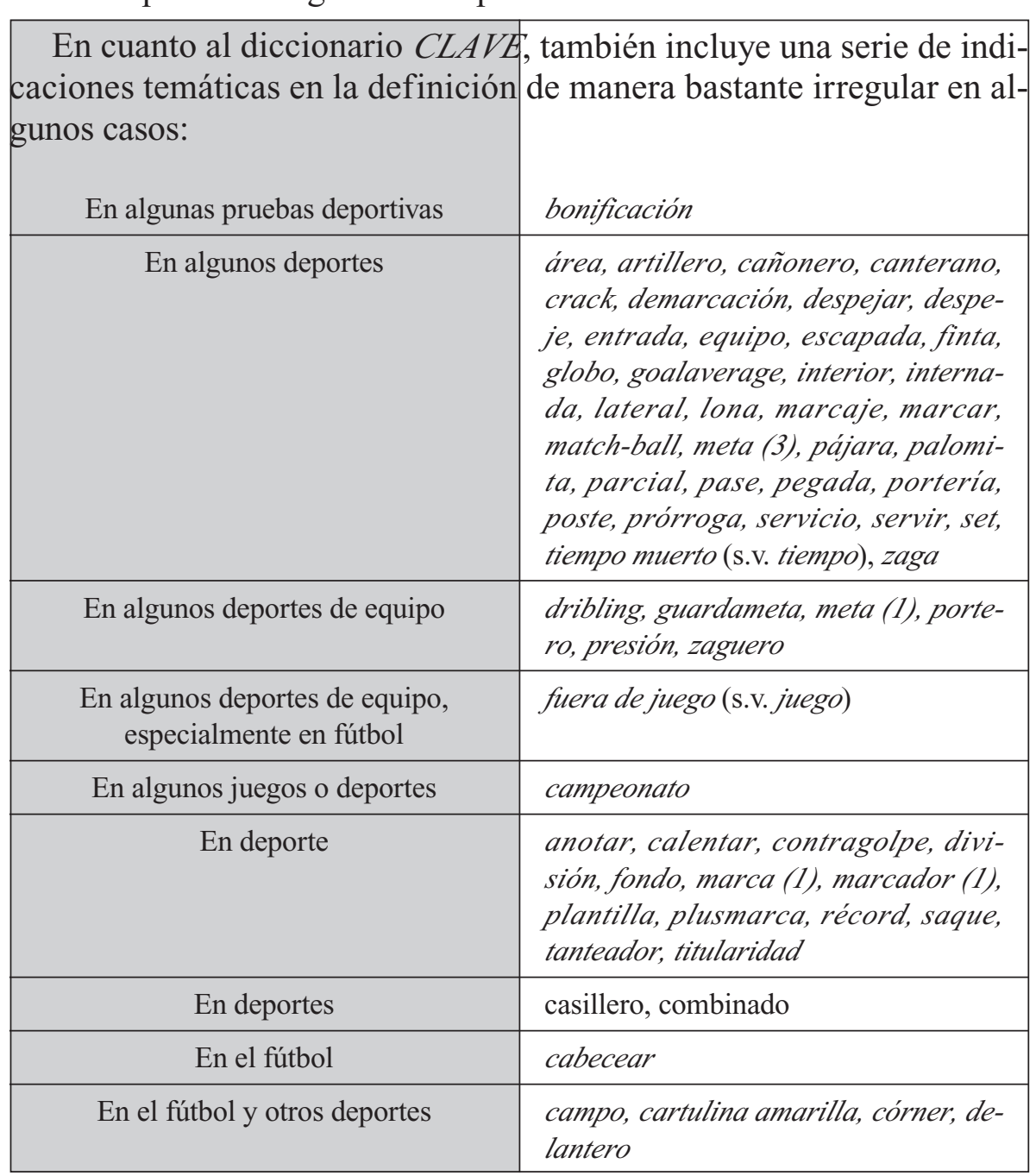




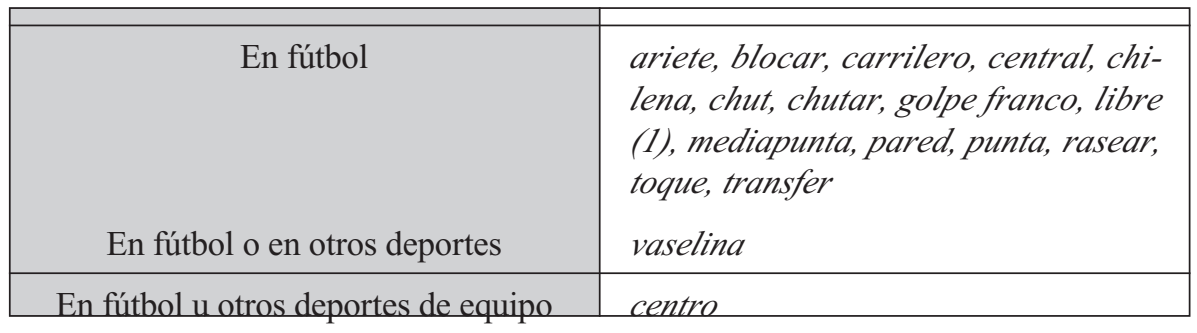

En fútbol y en otros deportes saque de esquina (s.v. saque)

En fútbol y otros deportes extremo, penalti, rematar

En un deporte banquillo, gol, goleada, golear

Tabla 15 - Indicaciones temáticas en las definiciones del CLAVE

Como puede observarse, la forma de establecer las indicaciones en la definición es, en muchos casos, irregular. He agrupado los tipos de indicaciones que podrían resumirse en una y que, en cambio, aparecen de modos diversos:

— "En el fútbol" y "En fútbol";

— "En deporte", "En algunos deportes" y "En un deporte";

_ "En fútbol y otros deportes", "En el fútbol y otros deportes", "En fútbol y en otros deportes", "En fútbol o en otros deportes

Por último, el $D E A$ es el diccionario que emplea menos indicaciones temáticas $\mathrm{y}$, además, el que las emplea en menos ocasiones ${ }^{41}$.

en determinados deportes y certámenes corona (I)

\begin{tabular}{cl}
\hline en deportes, especialmente en fútbol & gol \\
\hline en fútbol y otros deportes & extremo \\
\hline en determinados juegos de pelota & servir
\end{tabular}

41 Se trata, seguramente, de una consecuencia lógica por el hecho de incluir de manera bastante sistemática marcas temáticas referidas a distintos deportes y al deporte en general (véase 2.2.1.1) 
Tabla 16 - Indicaciones temáticas en las definiciones del $D E A$

Estas cuatro indicaciones temáticas, que se hallan sólo una vez bajo un término de entre todos los incluidos del corpus, son casi anecdóticas, pues, como ya he señalado anteriormente, este diccionario emplea marcas temáticas nuevas referidas a distintos deportes o aspectos del deporte en general. Por ejemplo, en uno de estos casos, concretamente bajo gol, se emplea la marca Dep, esp Fút y, en cambio, se halla la indicación temática "en deportes, esp en fútbol", lo que conduce a sospechar que se trata de una omisión puntual.

A modo de resumen, cabe decir que las indicaciones temáticas suelen aparecer con demasiada frecuencia y de manera poco sistemática en los diccionarios generales de español -con la excepción del $D E A-$ aunque se trata, en realidad, de un aspecto que es difícil que el usuario pueda percibir. No obstante, convendría que los lexicógrafos sistematizaran esta cuestión porque se lograría con ello que los diccionarios fueran más útiles y eficientes. Este fenómeno se repite, en mayor o menor grado, en todos los diccionarios generales de español analizados y, por lo tanto, requiere una solución que consista bien en sistematizar todas estas indicaciones y reducirlas a la mínima expresión, bien en eliminarlas de los diccionarios y presentarlas en forma de marcas temáticas.

\subsubsection{Análisis del contenido}

Una de las mayores dificultades que se les presenta a los lexicógrafos es tener que definir las unidades léxicas pertenecientes a un campo de especialidad de un modo claro y sencillo en un diccionario general. Más concretamente, la dificultad está en lograr que la definición sea "una información sobre todo el contenido y nada más que el contenido de la palabra definida" (Seco 1987b: 20). Además, como señalan Jean y Claude Dubois:

L'activité essentielle du lexicographe est la définition. Mais définir une entrée est une activité complexe, puis que c'est ou résumer le contenu d'un mot, et par là la définition ressemble à une analyse sémantique, ou décrire l'objet auquel renvoie ce mot ou qu'il dénote, et 
par la définition ressemble à une analyse sémiologique (ou sémiotique) (1971: 84).

He analizado algunas definiciones que considero insatisfactorias porque no se ciñen propiamente a lo que los términos definidos designan en la realidad. He partido de la base de que un diccionario de lengua no puede incluir toda la información acerca de un término por la imposibilidad que supone tener acceso a toda la terminología de los distintos ámbitos de especialidad -aparte de que éste no es su cometido-, además de que

la definición lingüística, a diferencia de la definición terminológica, no suele incluir todas las características de una noción, sino aquellas que son necesarias para distinguirlas de otra noción dentro del sistema de la lengua (Ahumada 2001: 61).

Pero, como se verá a continuación, hay casos en los que no se definen los rasgos esenciales. Mostraré una definición de cada diccionario.

En el diccionario académico, se define el término fuera de juego (s. v. juego) como:

fuera de juego. Posición antirreglamentaria en que se encuentra un jugador, en el fútbol o en otros juegos, y que se sanciona con falta contra el equipo al cual pertenece dicho jugador.

No define ninguno de los aspectos característicos de este término: que en esta posición antirreglamentaria se halla un jugador atacante, que este jugador atacante se halla entre el último y el penúltimo jugador defensor cuando el balón sale de la bota de otro atacante, y que se trata de una infracción cuya ejecución debe realizarse mediante un tiro libre indirecto ${ }^{42}$.

Por lo que se refiere al $D G L E$, comentaré la definición del término

42 Nuestra intención no es la de llevar a cabo una discusión acerca de cuántos aspectos de los señalados deben recogerse en un diccionario general de español, pero está claro que una definición como la dada por el $D R A E$ no permite clarificar demasiados aspectos al usuario. 
conectar pases:

conectar (del ingl. connect; tomado del 1. connectere) 3 DEPORTES. Empalmar [un pase o jugada].

Es el único diccionario de español, de los cinco analizados, que recoge este término, pero no lo define satisfactoriamente. Este término se emplea en el fútbol americano cuando el quarterback $k^{43}$ pasa el balón a otro jugador de su mismo equipo para que éste realice un $d o w n^{44}$ o un touchdown ${ }^{45}$.

En cuanto al GDLE, define el término fútbol americano (s. v. fútbol) como:

2 fútbol americano: Deporte más parecido al s.m. DEPORTES rugby que al fútbol, que se practica esencialmente en Estados Unidos.

En primer lugar, se define en comparación al rugby ("un deporte más parecido al rugby que al fútbol”), como si se tratara de un deporte cuyas reglas básicas fueran de conocimiento general. Lo que sí es de conocimiento general es que el balón empleado es ovalado (diferente al del fútbol) y que se trata de un deporte en el que el contacto es el elemento predominante y que este contacto es violento, pero nada más ${ }^{46}$. Y en segundo lugar, no se definen sus rasgos esenciales. Si un usuario español cualquiera desconoce en qué consiste el rugby -que es lo más normal-, deberá atender a qué se dice bajo

43 Propongo la definición siguiente: "m. FútA. Jugador que se encarga de ordenar las jugadas de ataque y de realizar los pases, así como de iniciar las jugadas de carreras".

44 Propongo la definición siguiente: “m. FútA. Intento de que dispone el equipo atacante para avanzar en el terreno de juego. El equipo que posee el balón tiene cuatro oportunidades para avanzar diez yardas".

45 "(Voz inglesa.) Acción de cruzar la línea de gol con la pelota controlada, en el fútbol americano. s.m. DEPORTES (GDLE)".

46 Aunque creo que no es lo apropiado, si se desea establecer una comparación con otro deporte puede definirse en comparación con el fútbol, pues se trata de una realidad extralingüística cercana a la mayoría de hablantes de español. 
rugby. En este caso, lo adecuado sería que se definiera fútbol americano independientemente de su semejanza o de su diferencia con el rugby:

rugby (voz inglesa.) Deporte que se practica s.m. DEPORTES con un balón ovalado que se impulsa con las manos y los pies, en el que se enfrentan dos equipos de quince jugadores que intentan colocar la pelota detrás de la portería contraria o hacerla pasar por encima de la barra horizontal de esta portería de un puntapié.

Además, no se indica un rasgo característico de este deporte como el hecho de que la finalidad principal es que los jugadores anoten tantos corriendo con el balón hacia la meta contraria sin poder pasarlo hacia adelante. En el caso de querer pasarlo, deben de hacerlo hacia atrás. Así pues, es difícil que el usuario logre comprender el significado de fútbol americano a partir de la información facilitada por el GDLE.

En el diccionario CLAVE, atiendo a la definición del término all star $^{47}$ :

[all star (anglicismo)

\section{locución}

Deportista de élite que destaca en un deporte: El palacio de deportes se llenó para ver el partido de baloncesto en el que jugaba un famoso "all-star".

Notas: Pronunciación: [olstár].

Es cierto que se trata de un deportista "que destaca", pero sólo se aplica al baloncesto y hasta hace pocos años sólo se aplicaba al baloncesto profesional norteamericano $(N B A)^{48}$. Pero lo realmente importante de este término es que designa un partido que, en los Estados Unidos, enfrenta a los mejores jugadores de las dos conferencias (Este y

47 En locución y en notas el subrayado no es mío.

48 Siglas de National Basketball Association.

49 Siglas de Asociación de Clubes de Baloncesto. 
Oeste) en las que se divide el campeonato liguero y que en España enfrenta a un combinado de jugadores extranjeros contra uno de jugadores españoles de la Liga $\mathrm{ACB}^{49}$.

Y, por último, el $D E A$ es el diccionario que suele definir con menos precisión los términos del deporte del corpus. Un rasgo característico de este diccionario es que presenta unas definiciones muy escuetas. Los ejemplos que muestro son ilustrativos de esta metodología en la definición. Asimismo, la definición viene acompañada de un ejemplo de uso real ${ }^{50}$. Me centraré en las definiciones de los términos anti-fútboly Dream Team. El primero se define como:

anti-fútbol $m$ (Fút) Forma de jugar al fútbol contraria al verdadero fútbol. $\mid A b c$ 20.5.66, 99: Sus hombres han jugado ... a la defensiva, pero sin que, como en otras ocasiones, se pueda decir que nos han brindado el antifútbol.

Esta definición presupone, por lo menos, dos cosas: primero, que existe una forma verdadera de jugar al fútbol y, segundo, que el usuario la conoce, pues no se explica en ningún lugar. En realidad, el anti-fútbol es un modo de jugar al fútbol muy defensivo, a la italiana (catenaccio $)^{51}$. Suelen practicarlo aquellos equipos que juegan a no perder y que en ningún caso muestran interés en conseguir la victoria.

El término Dream Team sólo aparece en el DEA:

Dream Team (ing; pronunc corriente, /drím-tím/) $m$ (Dep) Equipo

50 En Gutiérrez Cuadrado (1999: 77-95), se lleva a cabo una serie de reflexiones acerca de la ejemplificación en los diccionarios de aprendizaje de la lengua. Su aportación es interesante en la medida que ordena y resume muchos aspectos controvertidos relacionados con la ejemplificación, lo que sirve para poder tenerlos en cuenta en futuros trabajos lexicográficos.

51 En un nivel más jergal, suele decirse también poner el autobuis.

52 Este término, aliterativo y de gran expresividad, fue creado por el redactor de la revista de deportes Sports Illustrated, en el número correspondiente al mes de febrero de 1991, Jack McCallum, con motivo de la participación de los mejores jugadores de baloncesto de la NBA para disputar los Juegos Olímpicos de Barcelona-92 con la selección nacional de Estados Unidos. 
formado por jugadores estrella. Tb fig, fuera del ámbito técn. | R.Besa Spaís 14.12.92, 9: El equipo de Cruyff transita por la mayoría de los campos españoles con tal aureola de Dream Team que casi nadie repara en la posibilidad de una derrota.

Se trata de un término que, en primer lugar, tiene dos acepciones ${ }^{52}$. La primera hace referencia al equipo de baloncesto norteamericano que disputó las olimpiadas en Barcelona'92, integrado por los mejores jugadores de la liga $N B A$. La segunda, y por extensión, alude al equipo de fútbol del F.C. Barcelona entrenado por Johann Cruyff ${ }^{5_{3}}$. Por otro lado, y como se ha podido observar, el término no se define con propiedad, pues hay muchos equipos formados por jugadores estrella que no se denominan de este modo.

\section{RECAPITULACIÓN}

Se ha podido comprobar que la presencia de la terminología deportiva en los diccionarios generales de español es todavía pobre: el caso más significativo es el del diccionario académico, que recoge un 17\% del total de términos que conforma el corpus utilizado para este estudio. De los otros cuatro diccionarios, el DGLE, el GDLE y el CLAVE no rebasan el $30 \%$ y el $D E A$ no supera el $39 \%$.

En cuanto a la utilización de las marcas temáticas se refiere, se ha observado que, en general, hay cierta falta de sistematicidad en los diccionarios; el $G D L E$ y el $D E A$ resultan ser los más sistemáticos y el $D E A$ el más innovador. En los diccionarios analizados, oscilan las marcas e indicaciones que aparecen en la tabla 17.

En este estudio se ha podido comprobar cómo se definen, aunque no sea en su totalidad, los términos del corpus. En la tabla 18, expongo una selección de términos que presentan definiciones que no se refie-

53 En esta acepción, lo utilizó por primera vez el periodista de TV3, Televisió de Catalunya Lluís Canut durante la retransmisión de un partido amistoso del trofeo de verano "Teresa Herrera" de A Coruña que enfrentaba al F.C. Barcelona y al São Paulo de Brasil en el año 1992. 


\begin{tabular}{|c|c|c|c|}
\hline Diccionarios & $\begin{array}{l}\text { Marcas } \\
\text { temáticas }\end{array}$ & $\begin{array}{l}\text { Marcas } \\
\text { lingüísticas } \\
\text { (anglicismo) }\end{array}$ & $\begin{array}{l}\text { Indicaciones temáticas } \\
\text { (sobre deporte y fútbol) }\end{array}$ \\
\hline$D R A E$ & $\begin{array}{l}\text { Dep. } \\
\text { Esgr. }\end{array}$ & Del ing. & $\begin{array}{l}\text { - en algunos deportes } \\
\text { - en deportes } \\
\text { - en el fútbol } \\
\text { - en el fútbol y otros deportes }\end{array}$ \\
\hline$D G L E$ & DEPORTES & $\begin{array}{l}\text { anglic. } \\
\text { ANGLICISMO } \\
\quad \text { ing. } \\
\text { voz ing. } \\
\text { voz inglesa }\end{array}$ & $\begin{array}{l}\text { - en deportes de equipo } \\
\text { - en el fútbol } \\
\text { - en el juego del fútbol } \\
\text { - en deporte } \\
\text { - en ciertos deportes } \\
\text { - etc. }\end{array}$ \\
\hline$G D L E$ & DEPORTES & $\begin{array}{l}\text { expresión } \\
\text { inglesa } \\
\text { voz inglesa }\end{array}$ & $\begin{array}{l}\text { - en algunos deportes } \\
\text { - en el fútbol } \\
\text { - en fútbol y otros deportes } \\
\text { - en ciertas pruebas deportivas } \\
\text { - en competiciones deportivas } \\
\text { - etc. }\end{array}$ \\
\hline CLAVE & -------------- & $\begin{array}{l}\text { Anglicismo } \\
\text { Del inglés }\end{array}$ & $\begin{array}{l}\text { - en algunas pruebas deportivas } \\
\text { - en algunos deportes } \\
\text { - en algunos deportes de equipo } \\
\text { - en deporte } \\
\text { - en deportes } \\
\text { - etc. }\end{array}$ \\
\hline$D E A$ & $\begin{array}{l}\text { Autom } \\
\text { Balonc } \\
\text { Cicl } \\
\text { Dep } \\
\text { Esgr } \\
\text { Fút } \\
\text { Híp }\end{array}$ & Ing & $\begin{array}{l}\text { - en determinados deportes y } \\
\text { certámenes } \\
\text { - en deportes, esp fútbol } \\
\text { - en fútbol y otros deportes } \\
\text { - en determinados juegos de pelota }\end{array}$ \\
\hline
\end{tabular}

Tabla 17 - Marcas temáticas, lingüísticas e indicaciones temáticas en los diccionarios 


\begin{tabular}{|c|l|}
\hline Diccionarios & Términos \\
\hline DRAE & extremo, fuera de juego, portero \\
\hline DGLE & $\begin{array}{l}\text { ariete, carrilero, conectar pases, cuartos de final, dejada, ex- } \\
\text { tremo, guardameta, libero, maratón, pivote, portero }\end{array}$ \\
\hline asistencia, cancerbero, centro, decatlón, drive, escolta, extre- \\
$\begin{array}{l}\text { mo, fuera de juego, fútbol americano, guardameta, portero, ta- } \\
\text { pón, tiro libre }\end{array}$
\end{tabular}

Tabla 18 - Algunos términos con definiciones insatisfactorias en los diccionarios

ren satisfactoriamente a la realidad que designan.

\section{CONCLUSIONES}

El deporte es un ámbito cuyo interés viene siendo creciente desde sus inicios y que está en boca de una sociedad que hace uso de su terminología. Una gran parte de esta terminología se ha incorporado ya a la lengua general. Pero esto no significa que se trate de un conjunto de términos menos especializado que otro, sino que es objeto de mayor divulgación. Si un campo como el de la medicina tuviera una divulgación semejante a la del deporte, su terminología sería conocida y usada por la mayoría, pues su constante aparición en todos los medios de comunicación provocaría que se conociera, aún careciendo de interés por ello, el conjunto de términos que la conforman ${ }^{54}$.

Los cinco diccionarios estudiados son relativamente recientes en

54 Sucede con términos de la medicina empleados en el deporte como ligamento, rotura fibrilar, isquiotibial, artroscopia, etc.

55 El fútbol nutre a la lengua de una gran cantidad de términos, lo que da cuenta de la repercusión social de este deporte y del uso, en consecuencia, de su terminología. 
cuanto a su fecha de publicación, lo que permite esperar que incluyan más términos relacionados con el deporte de los que recogen.

Los resultados del análisis de los datos me permiten concluir que debe haber una mayor presencia de la terminología deportiva, en general, y de la terminología del fútbol, en particular ${ }^{55}$, en los diccionarios generales de español. Asimismo, debería existir una mayor sistematicidad en cuanto a la marcación y la definición de los términos. En este último aspecto, el de las definiciones, he podido comprobar que los diccionarios suelen presentar poca regularidad, no sólo en la definición, sino también en las indicaciones temáticas que se dan dentro de la misma sobre el deporte en el que se emplea el término.

El hecho de que los deportes sean fenómenos de masas conlleva que los términos que se emplean aparezcan en los diversos medios de comunicación como nunca había sucedido con otro ámbito temático. Y cuando una terminología aparece tan abundantemente en los medios, se convierte en conocida y usada por los hablantes, se banaliza $^{56}$. En este sentido, los lexicógrafos deberían hacer más hincapié en la terminología empleada en los deportes, pues es muy usada por los hablantes a pesar de que no goza de prestigio en el mundo cultural y académico ${ }^{57}$. Los diccionarios de lengua, sobre

56 Se trata de un rasgo característico de la terminología del deporte que la diferencia del resto de disciplinas.

57 El hecho de que se cuente con tan sólo tres trabajos acerca de la terminología del deporte es muy significativo, sobre todo teniendo en cuenta la gran cantidad de materiales de que se dispone; v. J. M. Puyal Ortiga (1972), B. Rodríguez Díez (1981) y N. Faura (1994).

Además, si se compara la presencia de términos de otros ámbitos con los del deporte en los cinco diccionarios tratados y la repercusión de estos ámbitos en relación con el del deporte, se observa que existe una gran desproporción. En el diccionario académico, por ejemplo, se recogen 424 términos marcados con Astron. (astronomía), 337 con Biol. (bilogía), 1041 con Bot. (botánica), 1940 con Mar. (marina), etc. y sólo 119 con Dep. (deportes). 
todo los no normativos, tendrían que recoger mucha de la terminología deportiva que aparece actualmente en los medios de comunicación. Antes o después, el uso acabará por establecer y fijar la norma.

\section{BIBLIOGRAFÍA}

Ahumada LaRA, Ignacio (2001): "Problemas de la definición enciclopédica en las palabras especializadas", en Las lenguas de especialidad y su didáctica. Actas del Simposio Hispano-Austriaco, Tarragona, Universitat Rovira i Virgili, pp. 59-69.

ALVAR ESQUERRA, Manuel (1990): "Cincuenta años de diccionarios monolingües VOX", Simposio de lexicografia actual: elaboración de diccionarios, A Coruña, Real Academia Galega, pp. 65-85.

__ (1992): "Prólogo de la presente edición", Diccionario General Ilustrado de la Lengua Española, Barcelona, Biblograf, pp. XXXVII-XLI.

Alzugaray Aguirre, Juan José (1982), Extranjerismos en el deporte, Barcelona, Herakles Editorial Hispano Europea.

Castañón Rodríguez, Jesús (1998), El español en el deporte [http://www.el-castellano.com/duq.html].

DuboIS, Jean y Claude (1971): Introduction à la lexicographie: le dictionnaire, Paris, Larousse.

FAJARDO, A. (1994): "La marcación técnica en la lexicografía española", Revista de Filología de la Universidad de La Laguna, 13, pp. 131-143.

— (1997): "Las marcas lexicográficas: concepto y aplicación práctica en la lexicografía española", Revista de Lexicografía, III, pp. 31-57.

FAURA, Neus (1994). La innovació lèxica a les cròniques i les retransmissions futbolistiques. 3 volúmenes. Barcelona, Universitat de Barcelona. Tesis doctoral inédita.

Garriga Escribano, Cecilio (1991): "El diccionario monolingüe de E./L.E. Análisis y propuestas", Universitas Tarraconensis, XIV, pp. 151-173.

(1996): "La marca de irónico en el DRAE: de Autoridades a 1992", en E. Forgas (coord.), Léxico y Diccionarios, Tarragona, Universitat Rovira i Virgili, pp. 105-131. 
(1997): "Las "marcas de uso" en los diccionarios del español", Revista de Investigación Lingüistica, 1, pp. 75-110.

GILI GAYA, Samuel (1992): "Características de este diccionario", Diccionario General Ilustrado de la Lengua Española, Barcelona, Biblograf, pp. XXXI-XXXV.

GómEZ TORREGO, Leonardo (1995): "Extranjerismos de uso muy frecuente en el español actual y no recogidos por la RAE en su diccionario", en El léxico en el español actual: uso y norma, Madrid, Arco/Libros, pp. 365-382.

GutiéRREZ CUADRADO, Juan (1996): "Las marcas en los diccionarios para extranjeros", en P. Díez de Revenga y J. M. Jiménez Cano (eds.), Estudios de sociolingüística, Murcia, DM, pp. 95-106.

(1999): "Notas a propósito de la ejemplificación y la sinonimia en los diccionarios para extranjeros", en M. Neus Vila et al., Así son los diccionarios, Lleida, Universitat de Lleida, pp. 77-95.

HAENSCH, Günter (1997): Los diccionarios del español en el umbral del siglo XXI, Salamanca,Universidad de Salamanca.

Hartmann, R. R. K. y G. James (1998): Dictionary of Lexicography, London, Routledge.

MARCos PÉrez, Pedro Jesús (1971): Los anglicismos en el ámbito periodístico. Algunos de los problemas que plantean, Valladolid, Universidad de Valladolid.

MarTínez de Sousa, José (1995): Diccionario de Lexicografía Práctica, Barcelona, Biblograf.

MAYORAL ASENSIO, Roberto (1992): "Estratificación de la terminología. Estudio del anglicismo en el vocabulario de los deportes" en Tercer Simposio Iberoamericano de Terminología, Lleida, IULA-UPF, 1997, pp. 207-218.

NomDedeu Rull, Antoni (2001): "Marcas temáticas: hacia una sistematización de las marcas de deporte y de fútbol en los diccionarios generales del español" en Perspectivas recientes sobre el Discurso, León, AESLA-Universidad de León, pp. 211-212 (resumen). Texto completo en CD-ROM adjunto, $13 \mathrm{pp}$.

Nomdedeu Rull, Antoni y Melva Josefina Márquez Rojas (2001): "Los anglicismos en la terminología del fútbol: motivaciones y consecuencias lingüísticas", en Perspectivas recientes sobre el Discurso, León, AESLA-Universidad de León, p. 174 (resumen). Texto completo en CD-ROM adjunto, $13 \mathrm{pp}$.

PRATT, Chris (1980): El anglicismo en el español peninsular contemporá- 
neo, Madrid, Gredos.

Puyal Ortiga, Joaquim Maria (1972): Aportación al estudio de las lenguas especiales: Terminología futbolística, Barcelona, Tesis de Licenciatura.

Rico, Francisco (1996): "El diccionario de la Academia y "los otros"”, "Prólogo" a Gran Diccionario de la Lengua Española, Barcelona, Larousse Planeta.

RodríGuez DíEz, Bonifacio (1981): Las lenguas especiales. El léxico del ciclismo, León, Colegio Universitario de León.

SAN ViCENTE, Félix (1998): "Sobre el registro de extranjerismos deportivos en la lexicografía actual" en Maria Vittoria Calvi y Félix San Vicente, La identidad del español y su didáctica, Lucca, Mauro Baroni, pp. 33-48.

SECO, Manuel (1987a): "El "contorno" en la definición”, Estudios de lexicografía española, Madrid, Paraninfo, pp. 35-45.

(1987b): "Problemas formales en la definición", Estudios de lexicografia española, Madrid, Paraninfo, pp. 15-34. 